\title{
A multi-center, signal-arm study on cancer patients' perception of chemotherapy side effects, depression, and decision regret at the end of adjuvant treatment
}

\author{
Caterina Calderon ${ }^{1}$, Raquel Hernández², David Gómez ${ }^{3}$, María del Mar Muñoz ${ }^{4}$, Alba Rosa Díez², Eva Martínez de Castro ${ }^{5}$, \\ María Ángeles Vicente ${ }^{6}$, Laura Ciria-Suarez ${ }^{1}$, Marta Oporto-Alonso ${ }^{1}$, Paula Jiménez-Fonseca ${ }^{3}$
}

Cite this article: Calderon $C$, Hernández R, Gómez D, Muñoz del MM et al: A multi-center, signal-arm study on cancer patients' perception of chemotherapy side effects, depression, and decision regret at the end of adjuvant treatment. Asia-Pac J Oncol 2020; 1: 31-37. https:// doi.org/10.32948/ajo.2020.09.22

\begin{abstract}
Purpose The aim was to assess patients' perception of chemotherapy side effects and analyze the relationship between these, depression, and treatment rejection.

Methods A multi-center, signal-arm study in 456 patients with resected, non-metastatic cancer. Conducted upon completion of adjuvant chemotherapy. Participants answered questionnaires evaluating chemotherapy side effects (EORTC-QLC-C30), depression (BSI), and decision regret (DRS).

Results The three most common symptoms reported by the patients were fatigue $(57.5 \%)$, insomnia $(56.7 \%)$, and pain (31\%). Only $7.6 \%(n=35)$ expressed regret over having opted to receive adjuvant chemotherapy. Fatigue, insomnia, dyspnea, and pain were associated with more depression, while fatigue, pain, and age were associated with decision regret.

Conclusion Healthcare professional should consider decreasing fatigue, insomnia, and pain a priority if quality of life is to be improved for patients receiving chemotherapy. The treatment of the side effects of chemotherapy for cancer is essential to improve the quality of life and compliance with the treatment.
\end{abstract}

Key words adverse events, adjuvant therapy, anticancer drugs, EORTC-QLC-C30, fatigue, toxicity

\footnotetext{
1. Department of Clinical Psychology and Psychobiology, Faculty of Psychology, University of Barcelona, Spain.

2. Department of Medical Oncology, Hospital Universitario de Canarias, Tenerife, Spain.

3. Department of Medical Oncology, Hospital Universitario Central of Asturias, Oviedo, Spain.

4. Department of Medical Oncology, Hospital Virgen de La Luz, Cuenca, Spain.

5. Department of Medical Oncology, Hospital Universitario Marqués de Valdecilla, Santander, Spain.

6. Department of Medical Oncology, Hospital Universitario Morales Meseguer, Murcia, Spain.

Correspondence: Dr. Caterina Calderon ( Department of Clinical Psychology and Psychobiology, Faculty of Psychology, University of Barcelona, Passeig de la Vall d'Hebron, 171. 08035 Barcelona, Spain; Email address: ccalderon@ub.edu).
} 


\section{Introduction}

Cancer is a serious healthcare issue that greatly impacts patients and their relatives [1]. This is due to disease itself and the therapies. Chemotherapy is one of the mainstays of treatment and often causes uncomfortable side effects. Some of these are isolated during the days following chemotherapy administration, but others persist for a time after completing treatment $[2,3]$ negatively affecting patient's quality of life (QoL) [2], activities, as well as their family or social life [3], and cause depression [4].

Likewise, unsuccessful control of chemotherapy toxicity can affect treatment efficacy, given the need to decrease doses, prolong intervals, or terminate it prematurely [4], and lead to the patient being discontent with or rejecting treatment [5].

This study sought to assess patients' perception of chemotherapyassociated side effects upon completion of adjuvant chemotherapy, as well as to analyze the relation between side effects, depression, and treatment rejection.

\section{Materials and methods}

\section{Participants and procedure}

This multi-institutional, prospective, transversal research design study pooled consecutive patients recruited at 14 hospitals in Spain. The study was approved by the Ethics Review Board at each institution. Inclusion criteria required aged 18 years or older, had a resected non-advanced, solid tumor, eligible for adjuvant treatment. Individuals with metastatic disease, first-time recipients of adjuvant therapy, treated with preoperative radio- or chemotherapy, or with adjuvant hormone therapy or radiotherapy without chemotherapy were excluded. Patients were included in the study at the beginning of chemotherapy by completing various questionnaires and several of these scales were refilled at the end of adjuvant chemotherapy. Patients who had completed the end-oftreatment questionnaires were considered for this analysis.

\section{Measure}

Participants' characteristics and those of their tumor were recorded by means of an interview and their clinical history. Toxicity, depression, toxicity, decision regret and the interference of chemotherapy with daily activities were measured through questionnaires filled out by the patients themselves.

\section{Chemotherapy side effects}

It was measured using the European Organization for Research and Treatment of Cancer QoL questionnaire instrument (EORTC QLQ-C30) [6]. The scale contains 30 items grouped into three scales: functional scale, symptoms scale and global health status. Scores for each item range from 0 to 100 . Higher functional scale and global health status scores and lower symptoms scale scores indicate better QoL (in this sample $\alpha=0.85$ ).

\section{Depression}

It was measured by using the six-item depression subscale from the Brief Symptom Inventory (BSI) [7]. The BSI-6 assess the dimension of depression, ranging from sadness to suicidal symptoms [7]. Respondents were asked to answer based on how they had felt over the previous seven days; each item was rated on a five-point Likert scale from 0 (no at all) to 4 (extremely); scores on scale ranged from 0 to 24 with higher scores indicating greater depression. Raw scores are converted to T-scores based on genderspecific normative data. The test-retest reliability ranged from
0.78 to 0.90 . In the present study, internal consistency (Cronbach's alpha) was 0.75 .

\section{Decision Regret}

It was measured by the Decision Regret Scale (DRS) which is a five-item to evaluate decisional regret [8]. The DRS is a self-report scale to evaluate decisional regret. Items are scored on five-point Likert scales, ranging from 1 to 5 . Scores were reversed for items 2 and 4 ; mean scores were obtained and the converted by subtracting 1 and multiplying by 25 . Scores range from 0 to 100 , with higher scores indicating greater regret. Internal consistency reliability estimates (alpha) range from 0.81 to 0.92 for oncology patients [9].

\section{Interference with activities}

It was measure using the EORTC QLQ-C30 three-item interference activities subscale [6].

\section{Statistical analysis}

Descriptive statistics were reported for demographic information. Independent t-test were performed to assess differences in spirituality scales based on sociodemographic and clinical characteristics. Pearson's chi-square test was used to evaluate association between chemotherapy side effects, depression, and decision regret. Different hierarchical multiple linear regression analyses were performed to examine the influence of chemotherapy side effects on depression and decision regret, with adjustment for sociodemographic and clinical variables. Those sociodemographic and clinical variables that were significantly related to chemotherapy side effects in the univariate analysis were introduced into the linear regression analysis. Statistical analyses were performed with Statistical Package for Social Sciences (SPSS) software (IBM-SPSS for Windows, version 23.0).

\section{Results}

\section{Baseline characteristics, side effects and decision regret}

From June 2015 to August 2018, 746 patients were recruited; 63 failed to meet inclusion criteria. Finally, 456 subjects were included and their basal characteristics are shown in the table 1. All had undergone curative oncology surgery and received adjuvant chemotherapy. Patients were mostly (83\%) treated with the following chemotherapy regimens: fluoropyrimidine $+/-$ oxaliplatin, doxorubicin + cyclophosphamide + paclitaxel, cisplatin + vinorelbine, gemcitabine, temozolomide. Monotherapy was administered in $23.2 \%$, while $75.2 \%$ received a combination of two or more drugs.

After completing chemotherapy, patients most frequently reported: fatigue $(57.5 \%)$, insomnia $(56.7 \%)$, and pain $(31 \%)$. In $51.9 \%$, side effects interfered with social activities, with family life in $43.0 \%$, and $20.0 \%$ had symptoms interfering with everyday activities.

When asked about their satisfaction with the decision to accept adjuvant treatment, only $7.6 \%(\mathrm{n}=35)$ said they deeply regretted receiving treatment.

\section{Perception of side effects by gender, age and tumor characteristics}

The most frequent side effects were nausea/ vomiting, insomnia, and pain in both genders and across all age groups (table 2). Women reported significantly more fatigue, pain, dyspnea, and insomnia than men. Individuals under the age of 54 experienced more fatigue and pain than people over 65 years. 
Table 1. Participant characteristics $(n=456)$.

\section{Baseline characteristics}

Gender: $\mathrm{n}(\%)$

Women

Men

Age (years): mean (SD)

Marital Status: n (\%)

Married/partnered

Without partnered

Educational level: n (\%)

Primary

Medium

Employment status: n (\%)

Active

Retired or unemployed

Cancer localization: $\mathrm{n}(\%)$

Colorectal

Breast

Others

Cancer stage: n (\%)

$$
\text { I-II }
$$

III

Type of treatment: $n(\%)$

CT

$\mathrm{CT}+\mathrm{RT}$

Type of chemotherapy (\%)

Monotherapy

$106(23.2)$

Combined

Abbreviations: CT: chemotherapy; RT: radiotherapy; SD: standard deviation; \%: percentage

Symptoms interfered more with social activities in females than males; likewise, women reported more depressive symptoms than men. In younger patients, symptoms interfered more with social, family, and daily living activities; additionally, these patients had more depression than older ones ( $>65$ years). There were no significant differences in the subjects' perception of their overall QoL by gender or age.
The most frequent side effects were fatigue, insomnia, loss appetite, and pain across tumor sites and stages. Women with breast cancer reported significantly more fatigue and pain than patients with colon cancer. Participants with other tumors reported significantly more nausea/vomiting and loss of appetite than breast and colon cancer patients. Individuals with stage III cancer had significantly more loss of appetite and diarrhea than patients with 
Table 2. Perception of side effects by gender and age.

\begin{tabular}{|c|c|c|c|c|c|c|c|}
\hline Side effects & $\begin{array}{l}\text { Male } \\
(n=203)\end{array}$ & $\begin{array}{l}\text { Female } \\
(n=253)\end{array}$ & $\begin{array}{l}\text { p value } \\
\text { (gender) }\end{array}$ & $\begin{array}{l}\leq 54 \\
(n=163)\end{array}$ & $\begin{array}{l}55-65 \\
(n=138)\end{array}$ & $\begin{array}{l}\geq 66 \\
(n=155)\end{array}$ & $\begin{array}{l}\text { p value } \\
\text { (age) }\end{array}$ \\
\hline Fatigue & $29.1(24.8)$ & $40.2(28.7)$ & 0.001 & $40.6(29.5)$ & $29.8(26.7)$ & $35.4(24.5)$ & 0.002 \\
\hline Nausea/vomiting & $11.9(20.5)$ & $10.6(20.1)$ & NS & $11.7(21.4)$ & 10.7 (20.9) & $11.5(18.1)$ & NS \\
\hline Pain & $16.3(21.9)$ & $21.8(27.8)$ & 0.021 & $25.1(29.0)$ & $14.9(22.8)$ & $18.3(23.1)$ & 0.002 \\
\hline Dyspnea & $3.6(12.7)$ & $8.5(21.2)$ & 0.004 & $8.4(21.1)$ & $4.0(15.3)$ & $7.1(17.6)$ & NS \\
\hline Insomnia & $23.2(27.8)$ & $37.3(37.0)$ & 0.001 & $35.3(35.9)$ & $26.2(33.3)$ & $31.2(31.4)$ & NS \\
\hline Loss of appetite & $20.2(29.9)$ & $21.1(30.5)$ & NS & $16.6(26.5)$ & $24.7(33.5)$ & $20.6(29.4)$ & NS \\
\hline Diarrhea & $19.3(28.3)$ & $15.2(26.5)$ & NS & $17.4(29.3)$ & $16.2(27.8)$ & $17.9(24.8)$ & NS \\
\hline $\begin{array}{l}\text { Overall quality of } \\
\text { life }\end{array}$ & $70.6(24.3)$ & $67.8(22.8)$ & NS & $66.8(23.8)$ & $69.6(24.6)$ & $70.6(22.1)$ & NS \\
\hline Anxiety & $58.9(6.8)$ & $62.0(7.7)$ & 0.012 & $62.0(7.3)$ & $59.5(7.2)$ & $60.4(6.3)$ & 0.009 \\
\hline Depression & $59.8(5.7)$ & $61.2(6.3)$ & 0.001 & $61.5(6.3)$ & $59.8(5.4)$ & $60.4(6.3)$ & 0.001 \\
\hline $\begin{array}{l}\text { Interference with } \\
\text { family life }\end{array}$ & $18.1(26.0)$ & $21.3(27.9)$ & NS & $27.7(29.7)$ & $12.9(23.5)$ & $19.4(25.8)$ & 0.001 \\
\hline $\begin{array}{l}\text { Interference with } \\
\text { social activities }\end{array}$ & $20.9(27.1)$ & $28.2(29.5)$ & 0.007 & $32.3(31.6)$ & $18.4(25.5)$ & $24.8(25.5)$ & 0.001 \\
\hline $\begin{array}{l}\text { Interference with } \\
\text { daily living activi- } \\
\text { ties }\end{array}$ & $11.4(16.5)$ & $14.6(18.7)$ & NS & $16.2(19.3)$ & $10.1(17.1)$ & $13.9(16.3)$ & 0.009 \\
\hline
\end{tabular}

Abbreviations: NS: no statistic significance.

cancer in stage I-II (table 3).

Subjects receiving a single cytotoxic agent stated that they suffered significantly more loss of appetite than those receiving two or more drugs. Participants being administered two or more cytotoxic agents had significantly more dyspnea than those receiving one drug. Patients with chemo and radiotherapy reported significantly more pain than patients with chemotherapy alone (table 4). There were no significant differences with respect to the remaining categories analyzed.

\section{Side effects as predictors of depression and decision regret}

The results of the correlation analysis indicated that all side effects scales were positively correlated with depression, and decision regret $($ all $p<0.001)$. The linear regression analysis predicting depression scores produced a significant regression $(\mathrm{F}(4,429)=63.847, \mathrm{p}=<0.001)$ and explained $36.9 \%$ of the variance in depression scores. Significant predictors of depression scores were fatigue, insomnia, dyspnea, and pain $(=0.246, \mathrm{p}=0.001 ;=0.285$, $\mathrm{p}=0.001 ;=0.111, \mathrm{p}=0.012$, and $=0.117, \mathrm{p}=0.026$, respectively). When the covariates were added to the analysis, no differences were detected.

In decision regret, the linear regression analysis showed that the fatigue and pain $(=0.209, \mathrm{p}=0.001$ and $=0.145, \mathrm{p}=0.018$, respectively), and age $(=0.095, \mathrm{p}=0.044)$ explained $9.6 \%$ of the variance in meaning scores $(\mathrm{F}(3,429)=18,878 \mathrm{p}=0.001)$.

\section{Discussion}

This study analyzes the presence of side effects in patients with cancer upon completion of adjuvant chemotherapy. In this series, chemotherapy provoked important side effects. It well known that the side effects of systemic chemotherapy on treatment of cancer are often severe. It is a worldwide problem that how to reduce the side effects from the chemotherapy. Volker et al. conducted a review on novel concepts to reduce the side effects of systemic cancer treatment. They focused on immunotherapy having the aim of reducing side effects and increasing long-lasting efficacy in cancer therapy. Therefore, the conventional chemotherapy, even if effective, can result in the serious side effects which have a limitation on its usage.

Fatigue and pain are two of the most common problems experienced by people with cancer. The level of fatigue and pain in this sample were considerable: half exhibited fatigue and almost one in three suffered pain. This is consistent with other studies in which fatigue and pain are beginning to be acknowledged as one of the most important, long-term consequences of cancer and its treatment [10]. Up to $85 \%$ of all individuals undergoing chemotherapy feel tired and weak [11], and between $20 \%$ and $50 \%$ complain of pain, a figure that soars to $90 \%$ in patients with metastatic or terminal disease [12]. In our sample in particular, females, patients with breast cancer, and younger participants reported fatigue and pain [13]. Fatigue and pain are two of the symptoms that produce the greatest distress among women with 
Table 3. Perception of side effects by tumor and stage.

\begin{tabular}{|c|c|c|c|c|c|c|c|}
\hline Side effects & $\begin{array}{l}\text { Colon Tumor } \\
(\mathrm{n}=205)\end{array}$ & $\begin{array}{l}\text { Breast Tumor } \\
(\mathrm{n}=143)\end{array}$ & $\begin{array}{l}\text { Others } \\
(n=108)\end{array}$ & p value & $\begin{array}{l}\text { I-II } \\
(n=243)\end{array}$ & $\begin{array}{l}\text { III } \\
(n=213)\end{array}$ & $\begin{array}{l}\text { p value } \\
\text { (Stage) }\end{array}$ \\
\hline Fatigue & $31.1(27.0)$ & $41.3(28.6)$ & $35.4(25.8)$ & 0.003 & $35.4(27.5)$ & $24.9(27.8)$ & NS \\
\hline Nausea/vomiting & $9.5(16.5)$ & 8.7 (16.8) & $18.1(24.1)$ & 0.001 & $9.5(18.3)$ & $13.0(22.0)$ & NS \\
\hline Pain & $15.2(23.3)$ & $23.7(27.3)$ & $21.9(26.1)$ & 0.044 & $19.6(25.8)$ & $18.3(24.3)$ & NS \\
\hline Dyspnea & $4.3(15.7)$ & 9.3 (21.7) & $6.4(16.7)$ & NS & $7.5(18.8)$ & $5.3(17.6)$ & NS \\
\hline Insomnia & $27.3(34.5)$ & $35.8(35.0)$ & $31.4(30.6)$ & NS & $31.3(32.6)$ & $29.9(35.2)$ & NS \\
\hline Loss of appetite & $20.9(31.4)$ & $15.3(25.3)$ & $28.0(32.7)$ & 0.005 & $17.5(27.6)$ & $24.1(33.1)$ & 0.025 \\
\hline Diarrhea & $19.1(29.2)$ & $12.3(22.6)$ & $19.6(28.9)$ & NS & $14.3(24.6)$ & $20.3(29.8)$ & 0.020 \\
\hline $\begin{array}{l}\text { Overall quality of } \\
\text { life }\end{array}$ & $69.5(24.0)$ & $66.7(23.2)$ & $68.2(23.3)$ & NS & $67.4(23.9)$ & $69.1(23.2)$ & NS \\
\hline Anxiety & $59.5(7.3)$ & $63.6(7.6)$ & $61.6(7.1)$ & 0.017 & $60.7(7.7)$ & $60.5(7.3)$ & NS \\
\hline Depression & $59.9(5.9)$ & $60.7(6.2)$ & $61.7(6.1)$ & NS & $60.3(6.2)$ & $60.9(5.9)$ & NS \\
\hline $\begin{array}{l}\text { Interference with } \\
\text { family life }\end{array}$ & $18.6(27.1)$ & $21.6(26.3)$ & $20.8(28.0)$ & NS & $19.2(25.7)$ & $20.3(29.3)$ & NS \\
\hline $\begin{array}{l}\text { Interference with } \\
\text { social activities }\end{array}$ & $23.5(29.3)$ & $26.5(27.2)$ & $27.1(29.3)$ & NS & $23.5(28.4)$ & $26.8(29.8)$ & NS \\
\hline $\begin{array}{l}\text { Interference with } \\
\text { daily living activi- } \\
\text { ties }\end{array}$ & $12.3(17.6)$ & $13.8(17.6)$ & $14.0(18.6)$ & NS & $12.0(16.8)$ & $14.4(19.1)$ & NS \\
\hline
\end{tabular}

Abbreviations: NS: no statistic significance.

breast cancer [3, 14]. Most patients report that fatigue and pain are major obstacles to carrying out daily activities and diminish patients' QoL [3]. Younger subjects also report frequent physical problems following chemotherapy, including fatigue, pain, loss of appetite, etc. [15]. Similarly, fatigue and pain may be related to the cancer's clinical characteristics (stage, surgical treatment, and tumor site) [12]. Moreover, there is evidence that chemotherapy and radiotherapy contribute to chronic pain [16], as we found in our study.

In our study, insomnia was present in more than half of the sample as seen in several previous series [17] and was more common in females than in males, with no differences detected based on age, tumor, stage, or treatment. Our results are consistent with previous studies that found higher levels of sleep disturbances in women undergoing chemotherapy [18] these have been related to increased fatigue, decreased QoL [17] and lower pain threshold [19].

In earlier works, an increase in side effects following treatment was associated with more symptoms of depression and worse QoL in patients with cancer [20]. Likewise, fatigue, pain, and age correlated with greater regret with respect to the treatment. Studies that have examined regret among cancer patients following treatment indicate that rejection has been associated with worse QoL and dissatisfaction with the care and information provided [5]. This work has certain limitations. First, the subjects may have found it hard to distinguish between side effects caused by chemotherapy and those due to the cancer surgery, age, or other drugs. Another limitation, associated with the cross-sectional nature of the study, is that the toxicity measured is the residual toxicity after completing adjuvant chemotherapy.

In general, our results reveal that the most prevalent side effects of chemotherapy for cancer were fatigue, insomnia, and pain. These symptoms can impair patients' psychological status and their satisfaction with treatment and the doctor-patient relationship. It is vital that toxicity be optimally treated as soon as it arises throughout treatment, as well as later on, both to maximize QoL, as well as to encourage patients' treatment compliance.

\section{Acknowledgments}

The authors grateful the investigators of the Neocoping study and the Supportive Care Working Group of the Spanish Society of Medical Oncology (SEOM) for their contribution to this study. We would like to thank Priscilla Chase Duran for editing and translating the manuscript. The IRICOM team for the support of the website registry, specially Natalia G. Cateriano.

\section{Funding}

This work was funded by SEOM in 2015. The sponsor of this research has not participated in the collection, analysis, or interpretation of the data, in the writing of the report, or in the decision to submit the article for publication. 
Table 4. Perception of side effects by drugs and treatment.

\begin{tabular}{|c|c|c|c|c|c|c|}
\hline Side effects & $\begin{array}{l}\text { One drug } \\
(n=106)\end{array}$ & $\begin{array}{l}\text { Two or more } \\
(n=350)\end{array}$ & p value & $\begin{array}{l}\text { Chemotherapy } \\
(n=319)\end{array}$ & $\begin{array}{l}\text { Chemo \& radiotherapy } \\
(\mathrm{n}=137)\end{array}$ & p value \\
\hline Fatigue & $31.2(25.8)$ & $36.7(27.9)$ & NS & $34.5(28.1)$ & $37.6(26.2)$ & NS \\
\hline Nausea/ vomiting & $12.8(21.5)$ & $10.7(19.8)$ & NS & $11.2(20.3)$ & $11.5(20.1)$ & NS \\
\hline Pain & $19.4(25.1)$ & $19.4(25.5)$ & NS & $17.9(25.0)$ & $23.2(26.3)$ & 0.040 \\
\hline Dyspnea & $3.1(14.2)$ & $7.5(19.2)$ & 0.029 & $6.1(17.5)$ & $7.1(19.6)$ & NS \\
\hline Insomnia & $29.8(30.6)$ & $31.4(34.7)$ & NS & $29.1(33.9)$ & $35.5(33.5)$ & NS \\
\hline Loss of appetite & $26.6(33.1)$ & $19.3(29.5)$ & 0.032 & $20.5(31.1)$ & $21.8(28.7)$ & NS \\
\hline Diarrhea & $19.0(29.9)$ & $16.2(26.3)$ & NS & $18.5(29.1)$ & $13.9(22.7)$ & NS \\
\hline Overall quality of life & $68.1(25.1)$ & $37.9(23.1)$ & NS & $68.4(23.7)$ & $66.8(23.1)$ & NS \\
\hline Anxiety & $60.1(7.7)$ & $60.8(7.4)$ & NS & $60.4(7.5)$ & $61.1(7.4)$ & NS \\
\hline Depression & $60.1(5.9)$ & $60.7(6.1)$ & NS & $60.5(6.1)$ & $60.7(6.1)$ & NS \\
\hline $\begin{array}{l}\text { Interference with fami- } \\
\text { ly life }\end{array}$ & $17.4(25.7)$ & $20.8(27.8)$ & NS & $19.9(27.6)$ & $20.5(26.6)$ & NS \\
\hline $\begin{array}{l}\text { Interference with social } \\
\text { activities }\end{array}$ & $21.9(27.2)$ & $26.3(29.6)$ & NS & $24.8(29.5)$ & $26.7(28.0)$ & NS \\
\hline $\begin{array}{l}\text { Interference with daily } \\
\text { living activities }\end{array}$ & $13.2(19.2)$ & $13.2(17.5)$ & NS & $13.1(17.6)$ & $13.6(18.2)$ & NS \\
\hline
\end{tabular}

Abbreviations: NS: no statistic significance.

\section{Author contributions}

$\mathrm{CC}$, and PJF designed the project, analyzed the data and drafted the manuscript. The other authors recruited patients, provided clinical information, comments, and improvements to the manuscript. All authors interpreted the data and review and approved the final manuscript.

\section{Competing interests}

The study has ethical adherence in all aspects, and its authors have no conflicts of interest. All authors meet the appropriate authorship criteria and no author has been omitted from the list.

\section{Ethical statement}

The study has been performed in accordance with the ethical standards of the Declaration of Helsinki and its subsequent amendments. This study is an observational trial without intervention.

\section{References}

1. Wilson MK, Karakasis K, Oza AM. Outcomes and endpoints in trials of cancer treatment: the past, present, and future. Lancet Oncol 2015; 16:e32-42. doi:10.1016/S1470-2045(14)70375-4.

2. Lewis C, Xun P, He K. Effects of adjuvant chemotherapy on recurrence, survival, and quality of life in stage II colon cancer patients: a 24-month follow-up. Support Care Cancer 2016; 24: 14631471.

3. Kluthcovsky ACGC, Urbanetz AA. Fatigue and quality of life in breast cancer survivors: a comparative study. Rev Bras Ginecol e Obs 2015; 37: 119-126. doi:10.1590/SO100-720320150005247.

4. Lorusso D, Bria E, Costantini A, Di M, Giovanni M, Annamaria R. Patients ' perception of chemotherapy side effects : Expectations , doctor - patient communication and impact on quality of life - An Italian survey 2017: 1-9. doi:10.1111/ecc.12618.

5. Fernandes-Taylor S, Bloom JR. Post-treatment regret among young breast cancer survivors. Psychooncology 2011; 20: 506-516. doi:10.1002/pon.1749.

6. Aaronson NK, Ahmedzai S, Bergman B, Bullinger M, Cull A, Duez NJ, et al. The European Organization for Research and Treatment of Cancer QLQ-C30: a quality-of-life instrument for use in international clinical trials in oncology. J Natl Cancer Inst 1993; 85: 365-376.

7. Derogatis LR. BSI 18, Brief Symptom Inventory 18: Administration, scoring and procedures manual. Minneapolis: NCS Pearson, Inc.; 2001.

8. Brehaut JC, O'Connor AM, Wood TJ, Hack TF, Siminoff L, Gordon E, et al. Validation of a Decision Regret Scale. Med Decis Mak 2003; 23: 281-292. doi:10.1177/0272989X03256005.

9. Calderon C, Ferrando PJ, Lorenzo-Seva U, Higuera O, Ramon y Cajal T, Rogado J, et al. Validity and Reliability of the Decision Regret Scale in Cancer Patients Receiving Adjuvant 
Chemotherapy. J Pain Symptom Manage 2019. doi:10.1016/ J.JPAINSYMMAN.2018.11.017.

10. Bower JE, Bak K, Berger A, Breitbart W, Escalante CP, Ganz PA, et al. Screening, assessment, and management of fatigue in adult survivors of cancer: An American Society of Clinical Oncology clinical practice guideline adaptation. J Clin Oncol 2014; 32: 18401850. doi:10.1200/JCO.2013.53.4495.

11. Pearce A, Haas M, Viney R, Pearson S-A, Haywood P, Brown C, et al. Incidence and severity of self-reported chemotherapy side effects in routine care: A prospective cohort study. PLoS One 2017; 12:e0184360. doi:10.1371/journal.pone. 0184360 .

12. van den Beuken-van Everdingen MHJ, Hochstenbach LMJ, Joosten EAJ, Tjan-Heijnen VCG, Janssen DJA. Update on Prevalence of Pain in Patients With Cancer: Systematic Review and Meta-Analysis. J Pain Symptom Manage 2016; 51: 1070-1090.e9. doi:10.1016/ j.jpainsymman.2015.12.340.

13. Kwekkeboom KL, Tostrud L, Costanzo E, Coe CL, Serlin RC, Ward SE, et al. The Role of Inflammation in the Pain, Fatigue, and Sleep Disturbance Symptom Cluster in Advanced Cancer. J Pain Symptom Manage 2018; 55: 1286-1295.

14. Palesh O, Scheiber C, Kesler S, Mustian K, Koopman C, Schapira L. Management of side effects during and post treatment in breast cancer survivors. Breast J 2018; 24: 167-175.

15. Laryionava K, Heußner P, Hiddemann W, Winkler EC. "Rather one more chemo than one less...": Oncologists and Oncology Nurses' Reasons for Aggressive Treatment of Young Adults with Advanced Cancer. Oncologist 2018; 23: 256-262. doi:10.1634/ theoncologist.2017-0094.

16. Schou Bredal I, Smeby NA, Ottesen S, Warncke T, Schlichting E. Chronic Pain in Breast Cancer Survivors: Comparison of Psychosocial, Surgical, and Medical Characteristics Between Survivors With and Without Pain. J Pain Symptom Manage 2014;48:852-862. doi:10.1016/j.jpainsymman. 2013.12.239.

17. Mystakidou K, Parpa E, Tsilika E, Pathiaki M, Gennatas K, Smyrniotis V, et al. The Relationship of Subjective Sleep Quality, Pain, and Quality of Life in Advanced Cancer Patients. Sleep 2007; 30: 737-742

18. Fakih R, Rahal M, Hilal L, Hamieh L, Dany M, Karam S, et al. Prevalence and severity of sleep disturbances among patients with early breast cancer. Indian J Palliat Care 2018; 24: 35.

19. Theobald DE. Cancer pain, fatigue, distress, and insomnia in cancer patients. Clin Cornerstone 2004; 6 Suppl 1D: S15-21.

20. Abrahams HJG, Gielissen MFM, Verhagen CAHHVM, Knoop H. The relationship of fatigue in breast cancer survivors with quality of life and factors to address in psychological interventions: A systematic review. Clin Psychol Rev 201. 